\title{
TRANSMISSION ELECTRON MICROSCOPY OF UNDERMINED PASSIVE FILMS ON STAINLESS STEEL
}

\author{
H. S. Isaacs, Y. Zhu, R. L. Sabatini \\ Department of Applied Science \\ Brookhaven National Laboratory \\ Upton NY 11973, USA \\ and \\ M. P. Ryan \\ Department of Materials \\ Imperial College of Science, Technology and Medicine, \\ Prince Consort Road, London, SW7 2BP,UK
}

\begin{abstract}
AECEMER

A study has been made of the passive film remaining over pits on stainfess 171939 steel using a high resolution transmission electron microscope. Type 305 stainless steel was passivated in a borate buffer solution and pitted in ferr $S T I$ chloride. Passive films formed at $0.2 \mathrm{~V}$ relative to a saturated calomel electrode were found to be amorphous. Films formed at higher potentials showed only broad diffraction rings. The passive film was found to cover a remnant lacy structure formed over pits passivated at $0.8 \mathrm{~V}$. The metallic strands of the lace were roughly hemitubular in shape with the curved surface facing the center of the pit.
\end{abstract}

\section{INTRODUCTION}

Evans, in 1927 described experiments to demonstrate that passivity was due to an oxide film which he separated from iron and aluminum by dissolving away the underlying metal with chloride or iodine containing solutions [1]. The survival of the passive iron oxide may be considered somewhat surprising as rapid dissolution of the iron in close proximity to the passive oxide in a chloride solution might be expected to lead to reductive dissolution of the oxide [2].

Chemical analysis of passive films separated from stainless steels, was accomplished by Vernon et al [3,4] and Mahala, Neilson and Rhodin [5-7] using iodine and bromine, respectively to dissolve away the metal. The latter authors also studied the films using transmission electron microscopy (TEM). They found the oxide films on Type 304, 316 and 347 stainless steels had no definitive crystallinity showing highly diffuse patterns by electron diffraction and somewhat more defined patterns for films formed on evaporated samples [5,7]. Passive films on stainless steels have also been observed by Yahalom, Ives and Kruger [8] after being undermined by halide pitting in aqueous solutions. Their TEM measurements showed four or five broad and diffuse rings with a fine grain-like morphology on the order of $2 \mathrm{~nm}$.

Films over the pits have been concluded to play an important role in the pitting process [9-12]. The growth of pits depends on maintaining the high concentratign 
halide metal dissolution products within the pit. If the concentration drops below a critical value the steel repassivates $[13,14]$. Pit covers have been considered to restrict diffusion of the concentrated dissolution products that collects in growing pits. Covers include the remaining passive film, and more visible layers composed of a porous metallic lacy structure over pits that have often been observed $[9,15-18]$.

Recently a model has been proposed to account for the formation of the lacy structure $[16,17]$. In the model the passive film covering the pit is considered to be destroyed or becomes ineffectual as a diffusion barrier at the growing edge of the pit producing an open hemispherical cavity. The concentration at the mouth drops rapidly below the critical concentration and the growing edge repassivates. Within the pit where the concentration remains sufficiently high the pit continues to dissolve and eventually produces a new surface perforation beyond the protected region. The mouth of the new perforation again repassivates following diffusional losses. The processes repeats itself leaving roughly interconnecting metal strips with increasing diameters having a lacy pattern. A finite element model of the processes has been shown to be consistent with the observed pattern [17].

The present study reports observations of the passive films present over pits on stainless steels including those associated with a lacy structure. Detailed measurements using high resolution TEM is shown to be directly relevant to the recent interest in the structure of passive films and the development of lacy pit covers.

\section{EXPERIMENTAL}

A JEOL 3000F field emission TEM was used in this study. It employs a high resolution pole piece with a point resolution of $0.165 \mathrm{~nm}, \mathrm{a} \pm 30^{\circ}$ tilt, a line resolution of $0.1 \mathrm{~nm}$ and $C C D$ cameras to record images and diffraction patterns.

The study was conducted on Type 305 stainless steel foil $15 \mu \mathrm{m}$ thick with a composition by weight per cent of $0.11 \mathrm{C}, 0.01 \mathrm{~S}, 0.45 \mathrm{Si}, 17.73 \mathrm{Cr}, 12.8 \mathrm{Ni}$ and 0.28 Mo. Disks $3 \mathrm{~mm}$ in diameter were punched from the foil. The disks were further thinned in $85 \% \mathrm{H}_{3} \mathrm{PO}_{4}$ at $3.3 \mathrm{~V}$ (all potential are given with respect to a saturated calomel reference electrode) for $2.5 \mathrm{~min}$ and then polished at $1.6 \mathrm{~V}$ for $2.5 \mathrm{~min}$. The disks were then held at a fixed potential in a pH 8.4 borate buffer for $5 \mathrm{~min}$. Ta clips were used to hold the disks during these treatments and on washing. The disks were then placed in a Pt basket and observed as they pitted at open circuit in a $0.3 \mathrm{M} \mathrm{FeCl}_{3}, 1 \mathrm{M} \mathrm{LiCl}$ solution. Subsequent washing was performed by stirring the Pt basket in large volumes of deionized water.

\section{RESULTS AND DISCUSSION}

After polishing the disks were treated to produce films with different passive oxide layer characteristics by polarization at different potentials in borate buffer. The potentials chosen were $0.2,0.8$ and $1.05 \mathrm{~V}$. At $0.2 \mathrm{~V}$ the potential was in the passive range about $1 \mathrm{~V}$ above where Fe passivates; $0.8 \mathrm{~V}$ was in the transpassive range; $1.05 \mathrm{~V}$ was where oxygen evolution begins to dominates the anodic current. Consideration was 


\section{DISCLAMMER}

This report was prepared 25 an 2000 unt of work sponsored by an agency of the United States Goverament. Neither the United Stutes Govermment nor any ageney thereof, aor any of their employees, makes any warraty, express of implied, or assumes any legai liability or responsibility for the aceuriey, completeness, or usefulness of any information, apparatus, produce, of process disedosed, or represents that its use would not infringe privately owned rights. Reference berein to any speciñe commercial produce, process, or service by trade anme, tradeconath, inanupae. turer, of otherwise does not necessarily constimite or imply its exdorsement, recommendation or favoring by the United States Govermment or any apency thereof. The views and opinions of authors expressed herein do not necessarily state or reflect those of the United States Government or any agency thereof. 


\section{DISCLAIMER}

Portions of this document may be illegible in electronic image products. Images are produced from the best available original document. 
given to the possibility that oxide growth could also take place when the steel was pitted in the $\mathrm{FeCl}_{3}$ solution. The redox potential in the $\mathrm{FeCl}_{3}$ solution, measured with $\mathrm{Pt}$ was 0.6 $\mathrm{V}$ and had a pH of about 0.8 . Taking into account the $60 \mathrm{mV} / \mathrm{pH}$ changes, the potential at $\mathrm{pH} 0.8$ correspond to a potential of $0.144 \mathrm{~V}$ at $\mathrm{pH} 8.4$. The potential of $0.2 \mathrm{~V}$ was chosen as the lowest potential because polarization at less than this potential may give rise to uncontrolled oxide growth in the pitting solution.

The passive oxide at $0.2 \mathrm{~V}$ in Figure 1 was amorphous with no indication of localized crystal structure. At $0.8 \mathrm{~V}$ indications of localized lattice ordering could be seen and the diffraction pattern showed weak rings. An example is shown in Figure 2 for an area of metal adjacent to the passive oxide. The metal showed a distinct (001) lattice image with cubic symmetry in contrast to the amorphous texture of the passive film. The diffraction pattern of this area, inset in Figure 2, shows the weak rings superimposed on the diffraction spots of the metal. At $1.05 \mathrm{~V}$ areas in the oxide with nanocrystallinity were more defined and were associated with fiber-like strands in the oxide. The structure of the passive film has been found to be dependent on the passivation time. Extended periods of time lead to a more crystalline oxide as has been shown by Ryan et al [19] and Marcus and his coworkers [20]. Similar studies of aging of passive films are planned.

Figure 3a shows a pit with a lacy pattern. The surface that had been pre-treated at $0.8 \mathrm{~V}$ in borate buffer. There is a tear in the passive oxide film that covered the pit. The area with the lacy structure is at an angle to the surface producing a relatively large gap between the corresponding edges of the tear. Figure $3 \mathrm{~b}$ is higher magnification of the center of the pit taken with a smaller objective aperture to increase the contrast and spatial resolution. Two features of the passive film are readily seen in the enlarged inset in Figure 3b. The round particles which were found to varying in size from about 5 to 40 $\mathrm{nm}$ and the dark fiber-like strands which were associated with the nanocrystalline sites of the film. Stereo micrographs showed the lacy structure in three dimensions as well as the general shape of the lace. The lace was made up of curved hemi-tubular sections. The rough edges of the hemi-tubes faced away from the center of the pit and the smooth outer walls faced the center of the pit.

The shape of the lace does not suggest an obvious process for its formation. The presence of the continuous undermined passive film over the pit and the rounded concave sides of the lace are inconsistent with the innovative model proposed for lace formation $[16,17]$. The model suggested that the contents of the growing pit readily diffuse away from the pit edge allowing it to repassivate. If the passivation did take place the edge on the concave side of the lace would be expected to be approximately perpendicular to original metal surface. However, the corresponding edge of the lace is rounded and the passive film apparently has no breaks adjacent to the lace. The presence of the passive film would be expected to inhibit diffusion at the pit edge.

In order to reconcile the proposed model with these observations one must assume that diffusion is possible through the undermined passive oxide. This seems unlikely since the very nature of passivity implies a that the passive film is an effective barrier. However, similar observations have been made for thin films pitting of 304 stainless steel which grew, apparently covered by an in tact passive film, for several minutes at very high current densities [21]. There must have been a significant diffusion path in this case. 
The possible routes are not obvious, either there must exist a level of porosity not discernable with the present measurements (i.e. $<1 \mathrm{~nm}$ scale) or the undermined film is indeed altered from that in contact with a metal surface such that diffusion through the oxide is possible. Such a change could be the formation of defects in the film on removal of the metal substrate or the selective dissolution of Fe from the film (perhaps caused by the reducing environment generated in the vicinity of the pit) resulting in atomic scale pores. Local chemical analysis will be performed to establish the composition of the oxide films under all formation conditions.

The tubular shape of the lace and many of the structures seen in the TEM image suggests that a form of tunneling plays an important role during pitting. At the center of the pit, where pitting probably started, a tunnel left a thumb shaped entity, and from the steriographic pair two tunnels could be seen leading from the "nail" of the thumb.

\section{CONCLUSIONS}

1) The passive film over pits on Type 305 stainless steel prepared by short passivation times of $5 \mathrm{~min}$ is predominantly amorphous. The appearance of local crystallinity increased with treatment at and above transpassive potentials.

2) The passive film over a lacy structure was continuous without breaks on the concave side of the lace strands.

3) The lace was hemitubular in shape with the walls facing the pit center. Other tubular shapes were present suggesting the formation of tunnels during pit growth.

\section{ACKNOWLEDGMENTS}

This research was performed under the auspices of the U.S. Department of Energy, Division of Materials Sciences, Office of Basic Energy Sciences under Contract No. DE-AC02-98CH10886.

\section{REFERENCES}

1) U. R. Evans, J. Chem. Soc. (London), 127, 1020 (19927).

2) P. Schmuki, S. Virtanen, A. J. Davenport and C. M. Vitus, J. Electrochem. Soc. 143, 576 (1996).

3) W. H. J. Vernon, F. Wormwell and T. J. Nurse, J Iron and Steel Inst., 150,81 (1944).

4) W. H. J. Vernon, E. A. Calman, C. J. B. Clews and T. J. Nurse, Proc. Roy. Soc., A126, 375 (1953).

5) E. M. Mahla and N. A. Nielsen, Trans. Electrochem Soc., 93,1, 339 (1948).

6) N. A. Nielsen, N. T. Rhodin, Zeit. Fur Elektrochemie 62, 707 (1958).

7) N. T. Rhodin, Corrosion, 12, t123 (1956).

8) J. Yahalom, L. K. Ives and J. Kruger, J. Electrochem. Soc. 120, 384 (1973).

9) L. Rosenfeld and I. S. Danilov, Corros. Sci., 7, 129 (1967).

10) H. S. Isaacs and G. Kissel, J. Electrochem. Soc. 119, 1628 (1972).

11) G. S. Frankel, L. Stockert, F. Hunkeler, and H. Boehni, Corrosion, 43, 429 (1987).

12) P. C. Pistorius and G. T. Burstein, Corros. Sci., 36, 525 (1994). 
13) G. T. Gaudet, W. T. Mo, T. A. Hatton, J. W. Tester, J. Tilly, H. S. Isaacs, and R. C. Newman, AIChE Journal, 32,949 (1986).

14) T. Hakkarainen, in Corrosion Chemistry within Pits, Crevices, and Cracks. A. Turnbull, Eds., HMSO Books, London, (1987).

15) J. Mankowski and Z. Szklarska-Smialowska, Corros. Sci., 15, 493 (1975).

16) P. Ernst, N. J. Laycock, M. H. Moayed and R. C. Newman, Corros. Sci., 36, 525 (1994).

17) N. J. Laycock, S. P. White, J. S. Noh, P. T. Wilson and R. C. Newman, J. Electrochem. Soc. 145, 1101 (1998).

18) R. P. Frankenthal and H. W. Pickering, J. Electrochem. Soc. 119, 1304 (1972).

19) M. P. Ryan, R. C. Newman and G. E. Thompson, J. Electrochem. Soc. 141, L164 (1994).

20) V. Maurice, W. P. Yang and P.Marcus, J. Electrochem. Soc. 145, 909 (1998).

21) M. P. Ryan, N. J. Laycock, H. S. Isaacs and R. C. Newman, J. Electrochem. Soc. In press. 


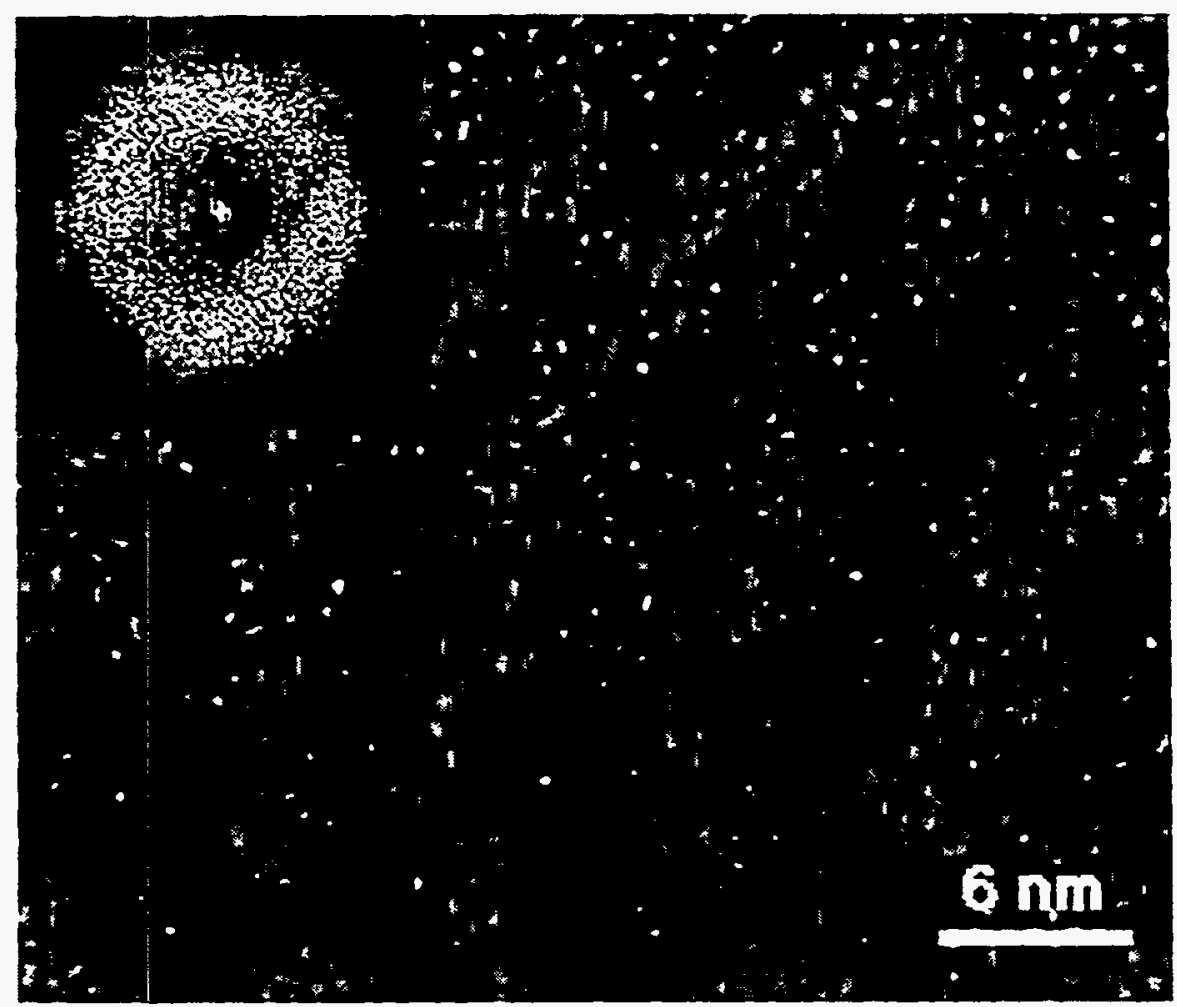

Figure 1. A high resolution TEM image showing the amorphous appearance of a passive film grown at $0.2 \mathrm{~V}$ in a borate buffer solution and undermined by pitting in a ferric chloride. The inset shows the diffraction pattern of the film

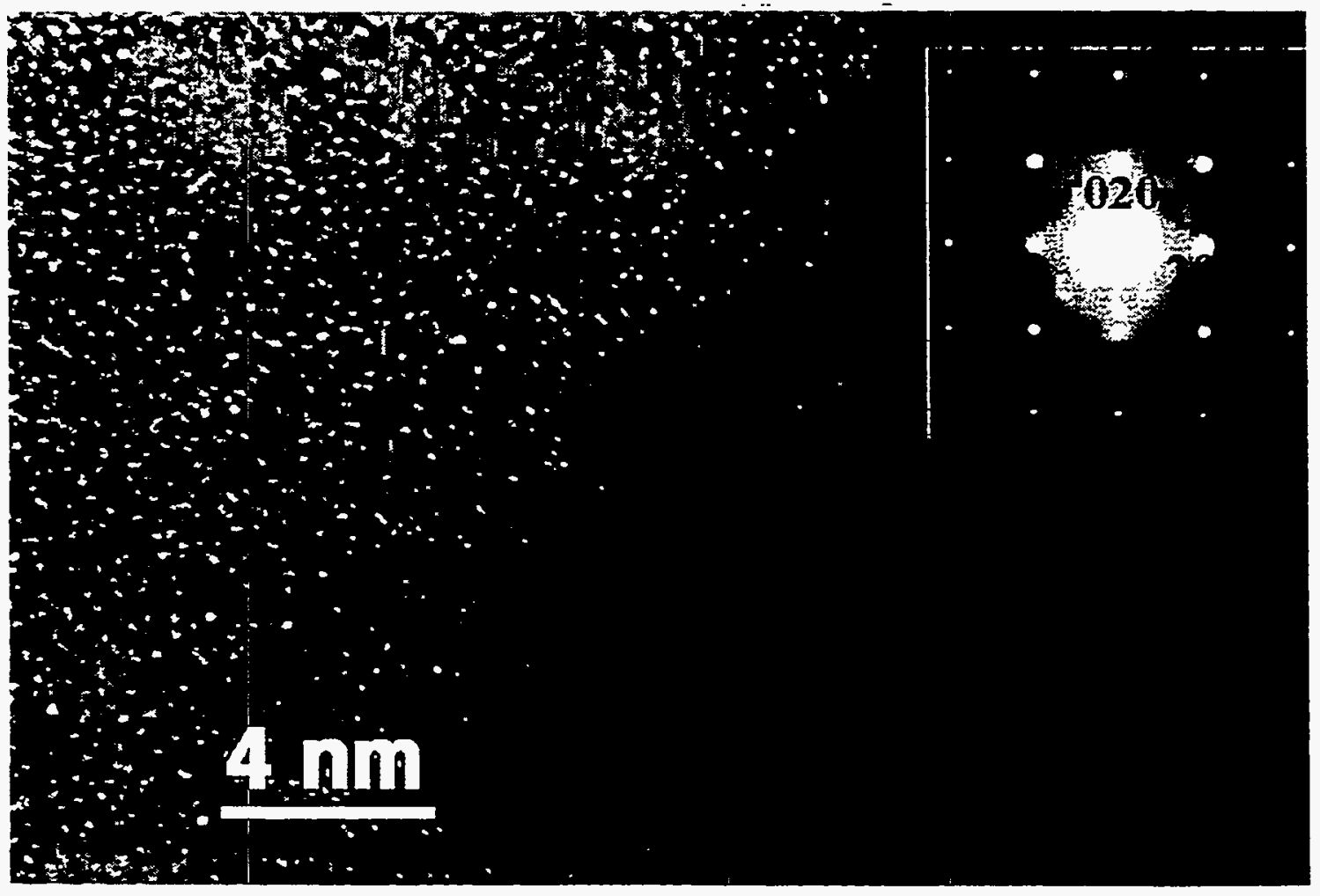

Figure 2. A high resolution TEM image of the steel and adjacent film grown at $0.8 \mathrm{~V}$. The inset shows the diffraction pattern of the metal and film 


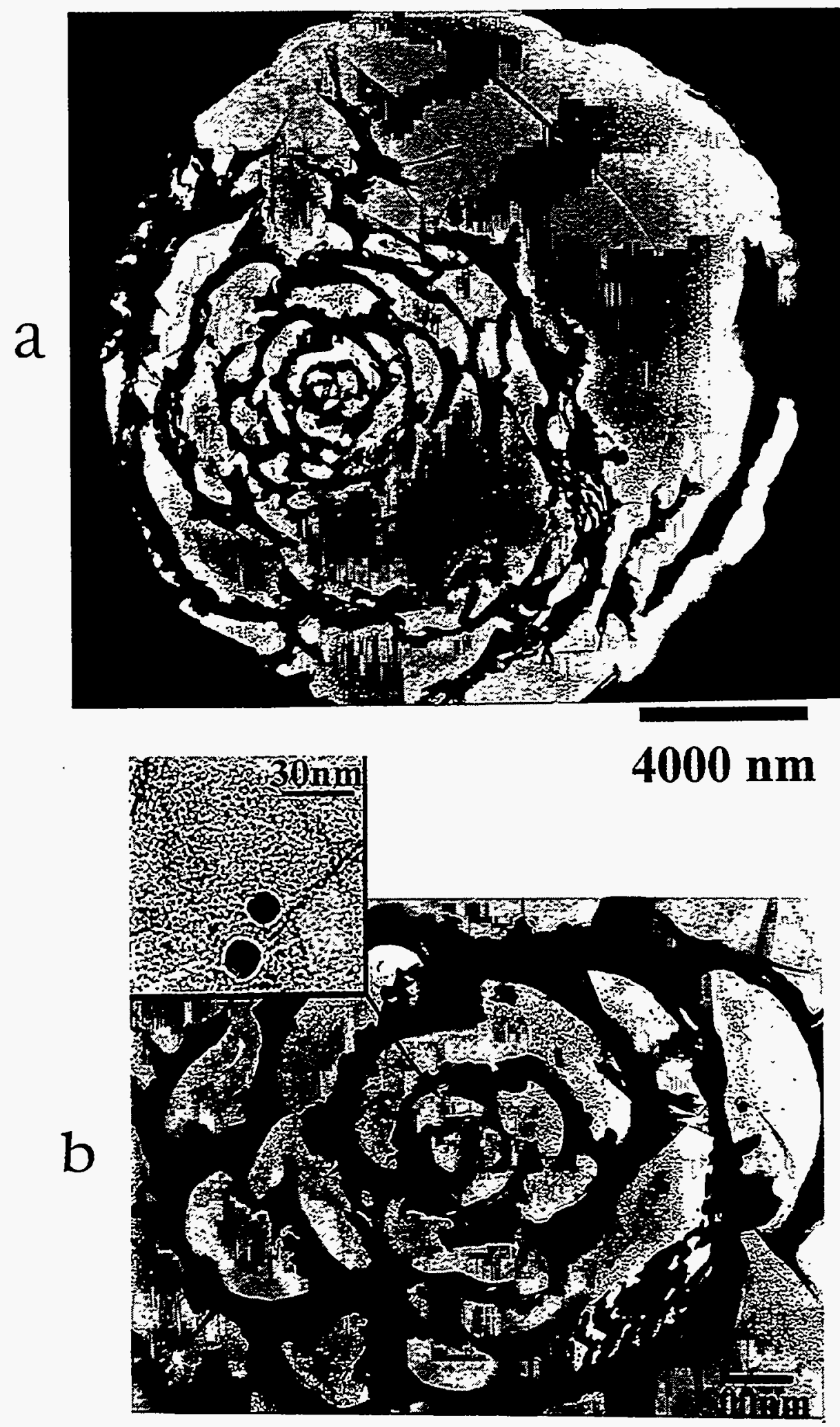

Figure 3. (a) TEM image of a pit showing a pit cover with the passive film and lacy structure. The passive film was grown at $0.8 \mathrm{~V}$ shows a distinct tear and the pit cover was at an angle to the surface. The passive film was grown at $0.8 \mathrm{~V}$. enlargement.

(b) An enlargement of the pit cover in (a) with an inset showing a further 